\title{
ANÁLISE DOS ESTILOS DE APRENDIZAGEM DE PÓS-GRADUANDOS EM EDUCAÇÃO À DISTÂNCIA
}

\author{
https://doi.org/10.29327/3860.11.20-6 \\ Ermano Batista da Costa ${ }^{1}$ \\ Halysson Oliveira Dantas ${ }^{2}$ \\ Tainá Macedo do $\mathrm{Val}^{3}$
}

\section{RESUMO}

A identificação dos estilos de aprendizagem facilita a conexão dos indivíduos, ao passo que a compreensão desses estilos traz impacto nas aulas virtuais, e é indispensável que os ambientes digitais propiciem aprendizagem significativa. Com isso, buscou-se analisar os estilos de aprendizagem de pós-graduandos em Educação a Distância em relação ao material didático e atividades do curso. A pesquisa descritivo-exploratória usou a abordagem quanti-qualitativa e ocorreu entre janeiro-fevereiro de 2019. A coleta de dados foi obtida por meio do questionário VARK online. A comunicação pesquisador-participante deu-se via e-mail e/ou WhatsApp. Os dados dos 72 participantes foram inseridos na planilha Excel e analisados por algoritmos. Posteriormente, as informações foram submetidas à estatística descritiva e à técnica de análise de conteúdo aplicada sobre o material didático e atividades. $O$ perfil predominante na pesquisa foi gênero feminino 52(72,20\%), participantes dos polos de Iguatu 24(33,30\%) e Russas 22(30,60\%), graduação principal em Letras 16(22,22\%), Pedagogia 10(13,89\%) e formação média de 7 anos, 41(56,94\%) concluindo a primeira especialização. Dos 11 estilos de aprendizagem encontrados, o mais prevalente foi VARK Type One 33(45,83\%), V mild e K mild 8(11,11\%), cada. As respostas tomadas diante das questões tiveram tendência a ler/escrever e sinestesia enquanto alunos, e variaram, se professor. O material de didático pareceu de acordo com os estilos de aprendizagem dos participantes. As atividades propostas estavam mais ligadas à leitura/escritura, havendo a necessidade de avaliações contendo recursos audiovisuais. É necessário o professor readaptar as formas preferidas de ensinar e diversificá-las, dados os diferentes estilos de aprendizagens dos alunos e que esses adaptem suas estratégias de estudo alinhadas às suas preferências.

Palavras-chave: Educação à Distância. Estilo de Aprendizagem. Material Didático. Teoria da Aprendizagem.

\footnotetext{
${ }^{1}$ Mestre em Odontologia, Especialista em Educação a Distância pela Universidade Estadual do Ceará.

${ }^{2}$ Doutor em Linguística pela Universidade Federal do Ceará e Professor da Unifanor/Wyden, Fortaleza, Ceará, Brasil ${ }^{3}$ Mestre em Ciências da Saúde, Pesquisadora pelo Diretório CNPq/Universidade Estadual do Ceará - Redes de atenção na perspectiva da saúde coletiva e enfermagem.
} 


\title{
ANALYSIS OF POST-GRADUANTS LEARNING STYLES IN DISTANCE EDUCATION
}

\begin{abstract}
The identification of learning styles facilitates the connection of individuals, while the understanding of these styles impacts on virtual classes, it is indispensable that digital environments provide meaningful learning. The aim of this study was to analyze the learning styles of post-graduate students in Distance Education in relation to didactic material and course activities. Descriptive-exploratory research used the quantitativequalitative approach and occurred between January-February 2019. Data collection was by VARK online questionnaire. The participant-researcher communication was given via email and / or WhatsApp. Data from the 72 participants were entered into the Excel worksheet and analyzed by algorithms. Subsequently, the information was submitted to descriptive statistics and the applied content analysis technique on didactic material and activities. The predominant profile in the research was female $52(72.20 \%)$, participants of the poles of Iguatu $24(33.30 \%)$ and Russas $22(30.60 \%)$, major graduation in Literature $16(22.22 \%)$, Pedagogy $10(13.89 \%)$ and average training of 7 years, 41 (56.94\%) concluding the first specialization. Of the 11 learning styles found, the most prevalent VARK Type One was 33 (45.83\%), V mild and K mild 8 (11.11\%), each. The answers to the questions tended to read / write and synaesthesia as students and varied as a teacher. The didactic material seemed to conform to the learning styles of the participants. The proposed activities were more related to reading / writing, and there was a need for evaluations containing audiovisual resources. It is necessary for the teacher to readapt the preferred ways of teaching and diversifying them, given the different learning styles of the students and that they adapt their study strategies in line with their preferences.
\end{abstract}

Keywords: Distance Education. Learning Style. Courseware. Theory of Learning.

\section{INTRODUÇÃO}

A preocupação com reflexões sobre a aprendizagem remonta os tempos da Grécia antiga. Mas somente a partir da segunda metade do século XX que o interesse por ela passou a se intensificar sistematicamente. A aprendizagem é um todo indissociável e precisa ser vista sob sua totalidade. Trata-se de um processo integrado e interiorizado ao homem em mobilização e em processamento (PARENTE; PINTO; CAMELO, 2014).

É indispensável que os ambientes digitais propiciem aprendizagem significativa e motivação, assim como disponibilizem informações para romper as 
sequências estáticas e lineares, o que deveria propiciar ao aluno um papel ativo na construção da aprendizagem, conforme seus interesses e necessidades. A construção da interatividade requer materiais educacionais suportados pelas teorias de aprendizagem de adultos, estilos de aprendizagem, taxonomia dos objetivos de aprendizagem e planejamento instrucional (ALMEIDA, 2003).

Com a identificação dos estilos de aprendizagem é possível somar esforços entre os docentes e a instituição visando buscar mecanismos que facilitem o processo de ensino e aprendizagem para melhorar a conectividade e a adaptabilidade. No momento em que o professor determina o ensino baseado nas preferências de aprendizagem dos alunos é um passo para estimulação de novas formas de aprendizado (LIZOTE et al., sem data). A aprendizagem acontece num processo de interatividade constante, em que os mundos internos e externos ao sujeito estão em permanente processo de transformação e construção social (PARENTE; PINTO; CAMELO, 2014).

Segundo Amaral (2017), o estudo do estilo de aprendizado de cada um deve ser objeto de pesquisas que busquem as melhores técnicas para ensinar, e consequentemente, gerarem aprendizado eficiente. E isso motivou a princípio a presente pesquisa. Diagnosticar qual o estilo predominante de aprendizado do aluno é importante para determinar as técnicas a serem adotadas na sala de aula física ou virtual (ZELADA, 2015).

A busca do desenvolvimento de competências em adultos pela utilização de tecnologia móvel sugere que determinados resultados educacionais sejam desejados. Assim, a compreensão dos estilos de aprendizagem das pessoas facilita o professor ou instrutor no desenvolvimento de atividades de ensino que produzirão os impactos desejados nos participantes dos cursos síncronos ou assíncronos (MIGUEL, sem data).

A Universidade Estadual do Ceará (UECE), a partir de 2017, ofertou o curso de especialização em Educação à Distância: fundamentos e ferramentas, composto por 11 disciplinas, dentre elas, Teorias da Aprendizagem, a qual se apresentou como a mais polêmica, seja pelos comentários dos fóruns, seja pelas mensagens do grupo da turma pela rede do aplicativo WhatsApp, bem como devido ao número de alunos que não atingiram a média final, tendo os mesmos que realizar tarefa de reforço e/ou prova de recuperação. No entanto, parte dos alunos conseguiu aprovação imediata, surgindo explicações prováveis para o fato, relacionadas talvez ao estilo de 
aprendizagem dos indivíduos. Por isso, foi mister saber se a notória dificuldade perante a disciplina Teorias da Aprendizagem deveu-se ao próprio assunto, bem como investigar se o conteúdo abordado no material didático e atividades da disciplina foram elaborados para atingir todas as formas apreciadas pelos alunos para aprender. Com essas motivações, buscou-se analisar os estilos de aprendizagem dos alunos do curso em relação ao material de estudo/atividades, e diante mão, traçando o perfil sócioeducacional dos pós-graduandos.

\subsection{EaD, recursos e ferramentas}

A EaD (Educação a Distância) é a modalidade de ensino mediada pelo uso de Tecnologias da Informação e Comunicação (TICs), podendo ou não apresentar momentos presenciais (MORAN, 2018).

No Brasil vê-se uma revolução impulsionada pelas múltiplas tecnologias configurando os movimentos no entorno e no cerne da educação como um todo e, nesse bojo, a EaD sofreu modificações e se expandiu em todas as direções do território nacional (EFFTING, 2010). Com o avanço das novas relações entre os processos educacionais e as novas TICs, a educação tem tentado promover o desenvolvimento do educando, com vistas a uma interação crítica (ALVES, 2011).

Frente ao imenso e multifacetado panorama educacional do ensino superior brasileiro, é fundamental que existam constantes reflexões da prática educadora, para que alunos, tutores e professores possam entender a complexidade da $\mathrm{EaD}$, visto ser formada por múltiplas dimensões humanas que interagem no Ambiente Virtual de Aprendizagem (AVA) perante os conteúdos (AZEVEDO, 2010; MAIA; VIDAL, 2013).

Independentemente do tipo de fórum que esteja sendo utilizado como espaço de construção de conhecimento, este deve ser acompanhado sistematicamente pelo professor/tutor, já que avaliar é mediar o processo de ensino e de aprendizagem. Além disso, é essencial que os alunos sejam orientados quanto à dinâmica do fórum, conscientizando-os da importância de sua participação ativa neste contexto de aprendizagem (PAIXÃO et al., 2016, p. 6). 
O vídeo pode ser um bom instrumento para problematizar e sistematizar as aprendizagens dos alunos, sendo dosado para maior assimilação das mensagens e o proveito possível das diversas linguagens audiovisuais utilizadas (ZANETTI, 2005).

A webconferência é um dos recursos didáticos mais eficazes e práticos da Internet, e tem por objetivo otimizar a comunicação entre pessoas, as quais conversam entre si. O tutor precisa conhecer a dinâmica de realização da webconferência, oportunizando a troca de experiências (SOUZA, 2015).

Atualmente, com a facilidade de acesso a software de edição de áudio e de vídeo digitais em computadores de uso pessoal, ampliou-se a possibilidade de criação e distribuição de materiais audiovisuais através da Web a um custo mais baixo. Contudo, é muito questionada a qualidade dessa produção quando é feita por pessoas que não possuem competência técnica para isso (ZANETTI, 2005).

\subsection{Material didático e atividades em EaD}

O processo de elaboração de apostilas demanda muito estudo, empenho e refazer de tarefas, tendo como objetivo abordar diversos aspectos do tema em uma linguagem acessível e correta (FLORINDO; BATISTA; AZEVEDO, 2015).

Os achados literários evocam a qualidade da sensibilidade, adequação, compreensão e inovação em material didático, também chamado material de estudo, como fatores para o um processo formativo em EaD bem sucedido (MACEDO, 2016).

\footnotetext{
A concepção de materiais didáticos para o ensino a distância é um processo que passa pelo reconhecimento das dimensões do processo educativo, pela análise e o levantamento de dados relativos à construção do conhecimento necessário e desejado e também pela questão da gestão pedagógica e administrativa que será necessária à implantação dos materiais escolhidos, sendo um desafio muito mais amplo do que apenas selecionar os conteúdos desejados (PACHECO; COELHO, 2012, p. 2).
}

Segundo Assis e Cruz (2011), nos cursos modelados a distância, e, em especial, no processo de elaboração de um material didático, saber a caracterização do público-alvo é um elemento indispensável por permitir que o aluno desenvolva ao longo do curso os propósitos pretendidos (ZANETTI, 2005). 
Belisário (2006) definiu critérios balizadores para nortear um processo de construção de um material didático em EaD: A) Navegabilidade: o material deve conjugar uma série de ferramentas de interação, reprodução de sons e imagens, destacando-se a articulação entre mídias, internet e a utilização do lúdico B) Estrutura: os conteúdos ofertados precisam ser resumidos, atraindo o estudante a aprofundar seus conhecimentos por outros caminhos. O material deve mostrar ainda relação teoriaprática transmitida por animações e vídeos. C) Discurso: vislumbra-se no material a dialogicidade, em que os textos sejam reproduzidos de forma a simular o diálogo entre o autor e o leitor; e a interatividade, que compreende a capacidade de tornar o diálogo concreto por ferramentas de interação.

Segundo Moran (2018) é possível dividir a evolução dos conteúdos digitais em três: (I) inicialmente os textos eram estáticos, uma simples transcrição do texto impresso para o meio virtual; (II) em um segundo momento os textos digitais passam a apresentar links e ferramentas para a cooperação entre os atores envolvidos em processos ensino - aprendizagem (III) e na atualidade, o conteúdo textual torna-se multimídia, viabilizado pela utilização do touchscreen e interativo. O uso do hipertexto digital viabiliza a mudança do conteúdo textual de estático para interativo.

As expressões estruturadas no material de estudo além de tratar do conteúdo formal de uma disciplina, orientam exercícios, atividades em AVAs, trabalhos escritos, pesquisas. Assim, as palavras precisam dizer mais do que um simples enunciado, elas precisam dialogar, causar impacto, despertar curiosidade e instigar outras buscas (EFFTING, 2010).

O processo de aprendizado virtual passa pela necessidade da existência de um processo de avaliação ou teste do aluno. O processo de postagem das tarefas é um instrumento que serve para refletir o processo de ensino e aprendizagem (QUINTANA; QUINTANA, 2012; BOKUMS; MAIA, 2016).

\subsection{A Aprendizagem e seus estilos}

As teorias da aprendizagem mais abordadas são as seguintes: behaviorista; humanista; cognitivista; sócio-histórica; e a andragogia (PARENTE; PINTO; 
CAMELO, 2014). Essas teorias unidas aos avanços recentes em outros campos do conhecimento, como a inteligência artificial, contemplam bem a aprendizagem.

\begin{abstract}
A Neurociência Cognitiva e suas vertentes Neuropsicologia e Neuroeducação têm sugerido que o construtivismo não cobre, sozinho, todas as necessidades da pesquisa educacional contemporânea e da complexidade de uma sociedade envolta pelas Tecnologias da Informação e Comunicação (PERES et al., 2014, p. 252).
\end{abstract}

$\mathrm{Na}$ abordagem tradicionalista o professor é o centro e o aluno é passivo no processo de ensino e aprendizagem. Já na proposta humanista este é protagonista. Para os comportamentalistas, os estímulos externos podem condicionar o comportamento dos indivíduos. A ênfase da abordagem cognitivista remete à interação (SILVA, 2017). A aprendizagem de adultos ou andragogia deve ser idealizada não só como resultado, mas na verificação de mudanças cognitivas e comportamentais nas relações dos indivíduos (MIGUEL, sem data).

Nos ambientes virtuais, as novas formas de aprendizagem podem ou não atender os diferentes estilos de aprendizagem (SILVA et al., 2013; LEONARDO; MOTA; GOMES, 2014). Um dos estudos feitos para detectar estilos de aprendizagem foi o Inventário VARK, nome decorrente do acrônimo inglês Visual, Aural, Read/Write e Kinesthetic (visual, auditivo, leitor/escritor e sinestésico). Esse modelo foi proposto pelos pesquisadores neozelandeses Neil D. Fleming e Colleen Mills em 1992, quando investigavam processos de ensino e aprendizado (AMARAL, 2017). Segundo Fleming e Baume (2006), o questionário do inventário VARK foi pensado para analisar situações reflexivas do dia a dia.

Os estilos de aprendizagem passíveis de identificação são representados pelos códigos: V, A, R, K (mild = fraco, strong = forte, very strong = muito forte $)-$ unimodal; VA, VR, VK, AR, AK, RK - bimodal; VAR, VAK, VRK, ARK - trimodal; VARK type one $=$ tipo um, VARK type two $=$ tipo dois, VARK transition $=$ transição panmodal, ainda podem ser agrupados em polimodal (bimodal + trimodal + panmodal), totalizando 25 opções (CARLOS, 2017).

A categorização de estilos de Witkin et al. (1977) possui um certo grau de generalidade e penetração. De acordo com esta abordagem, há duas formas de perceber 
a informação: de forma dependente (globalmente) ou de forma independente de campo (analiticamente).

Kolb (1984) baseou-se na teoria de aprendizagem experiencial para classificar os estilos de aprendizagem. Partindo da ideia de que aprender é transformar experiência em conhecimento. Dessa teoria derivou a de Honey-Alonso, em que a aprendizagem e o comportamento humano resultam da interação entre o ambiente, a experiência prévia vivida pelo aprendiz adulto e os conhecimentos construídos (Amaral e Barros, 2007).

É possível os alunos serem favorecidos por diferentes tipos de materiais, devido aos estilos de aprendizagem, em função da formação cultural, instrucional, idade e outros aspectos. Isso porque cada um tem formas particulares de perceber o mundo e de construir seu conhecimento (LEONARDO; MOTA; GOMES, 2014).

\section{METODOLOGIA}

\subsection{Tipologia do estudo}

Quanto ao objetivo a pesquisa é descritivo-exploratória e documental. Como abordagem adotou-se o método quanti-qualitativo. Uma pesquisa descritivoexploratória coloca o pesquisador diante do objeto de estudo, buscando explorá-lo com o objetivo de descrever as características de uma população ou fenômeno. Ao aprofundá-las é possível estabelecer relações de dependência entre variáveis, generalizando resultados (GIL, 2008).

Para Lüdke e André (1986), a análise documental visa analisar documentos na busca de identificar informações factuais nos mesmos e descobrir as circunstâncias de interesse. A pesquisa quantitativa parte do pressuposto de que é possível mensurar um determinado fenômeno (CASARIN; CASARIN, 2012). A pesquisa qualitativa trabalha com o universo de significados guiados pela subjetividade (MINAYO, 2009). Unidas, completam-se e complementam-se.

\subsection{Procedimentos de coleta de dados}


Serviram de participantes para a pesquisa 72 pós-graduandos que se matricularam no curso de especialização em Educação à Distância: fundamentos e ferramentas, que foi conduzido pela Universidade Estadual do Ceará a partir de 2017, tendo como polos Iguatu, Russas, Maranguape e Limoeiro do Norte.

Para a coleta de dados foi usado o questionário do modelo VARK, cujo resultado identifica como o respondente prefere aprender ou ensinar (AMARAL, 2017). Junto ao questionário VARK foram também coletados os dados socioeducacionais: gênero, graduação principal, tempo de graduação e qual o curso de pós-graduação. Para compor o estudo buscou-se questionar o material didático e as atividades realizadas junto à disciplina Teorias da Aprendizagem do curso.

A comunicação pesquisador-participante deu-se na última semana do mês de janeiro de 2019, via e-mail e/ou WhatsApp, ocorrendo as respostas até a primeira semana do mês seguinte, em que era respondido o questionário: https://docs.google.com/forms/d/e/1FAIpQLScqeKXcGwNHyiIqEddF7oT9eylL9q81ySmxVMM9Zc9alX2Bw/viewform?c=0\&w=1

\subsection{Análises dos Dados}

Os dados coletados pelo questionário foram inseridos no software Excel 2010 e enviados à empresa Vark Learn Limited, na Nova Zelândia, para identificação dos estilos de aprendizagem, por meio do algoritmo VARK e no retorno, as informações foram submetidas à estatística descritiva, $\mathrm{O}$ material de estudo e atividades do curso foram analisadas por meio da técnica de análise documental e de conteúdo, que segundo Bardin (2011) consiste nas seguintes etapas: a) pré-análise dos documentos (corpus de análise) b) formulação de hipóteses e/ou objetivos c) exploração do material com contagem (codificação), seleção das regras (classificação) e a escolha de categorias (categorização) d) tratamento dos dados com a interpretação referencial, reflexão e intuição com base nas relações que estabelecem os documentos, desvendando-os. Para Gomes (2001), a abordagem de análise de conteúdo explica o conteúdo por deduções 
lógicas e justificadas, tendo como referência sua origem, contexto e efeitos das mensagens a partir da visão do pesquisador.

Foram caracterizados como documentos os materiais de estudo e atividades do curso em $\mathrm{EaD}$, aqueles observados conforme os direcionamentos dos autores Belisário (2006) e Moran (2018), e estas analisadas na perspectiva das TICs, correlacionando-os aos estilos de aprendizagem analisados no presente estudo.

\subsection{Aspectos éticos}

Esta pesquisa foi conduzida de acordo com os preceitos determinados pela Resolução 466/12 para estudo com seres humanos, do Conselho Nacional de Saúde do Ministério da Saúde, sendo de livre acesso pela empresa Vark Learn Limited para o uso do questionário. Quanto à coleta de dados envolvendo os seres humanos, obteve-se consubstanciação do Comitê de Ética em Pesquisa da Universidade Estadual do Ceará, sob o parecer de número 3.126.574.

\section{RESULTADOS E DISCUSSÃO}

\subsection{Dados sócio-educacionais}

Quanto ao gênero, os participantes da pesquisa foram representados em 52 $(72,20 \%)$ pelo sexo feminino e $20(27,80 \%)$ pelo sexo masculino (dados não apresentados).

A mulher na contemporaneidade ampliou a sua capacidade de interagir e participar em muitos setores da sociedade, contrariando a história de negação social e silenciamento intelectual em suas diferentes realidades no contexto brasileiro (SANTIAGO; PIMENTEL, 2014). Com a maior participação das mulheres no presente estudo, observa-se a crescente atuação das mesmas na educação como discentes e docentes frente ao direito educacional nas legislações brasileiras. 
Os participantes eram pós-graduandos advindos dos polos de Iguatu 24 (33,30\%), Russas 22 (30,60\%), Maranguape 11 (15,30\%) e Limoeiro do Norte 15 (20,80\%), como explícito no Gráfico 2.

\section{Gráfico 1 - Distribuição percentual dos participantes quanto ao polo da especialização, EaD - UECE, 2018.}

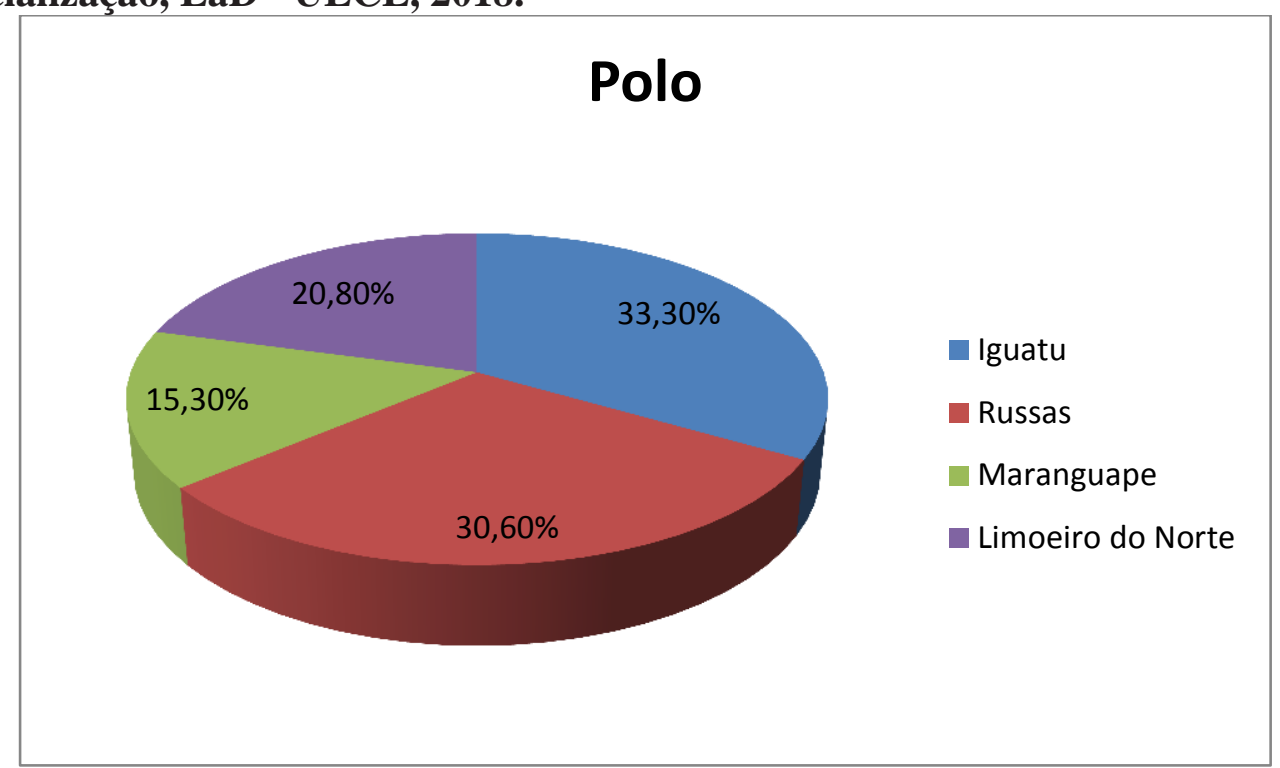

Fonte: elaboração dos autores.

Quanto ao tempo que haviam concluído a principal graduação, os números variaram de 1 a 17 anos, com média aritmética de 7 anos (dados não apresentados). Destaca-se a importância da oportunidade de acesso à especialização em Educação a Distância: fundamentos e ferramentas, oferecidos gratuitamente e na modalidade EaD pela Universidade Estadual do Ceará, beneficiando certos indivíduos que apesar de longo tempo que haviam se graduado, só agora estavam realizando uma pós-graduação (56,94\%). É fato que na Constituição Federal Brasileira (BRASIL, 1888. Art. 205, 206 e 210) está determinado que a educação seja direito de todos e dever do Estado, exercida com a colaboração da sociedade, devendo haver igualdade de condições para o acesso e liberdade de aprender. Situação essa bem fundamentada pela disponibilização de 4 polos regionais de educação presenciais para a especialização, nos municípios de Iguatu, Russas, Limoeiro do Norte e Maranguape.

Sobre a graduação principal, informada pelos participantes, destacaram-se os cursos da grande área de ensino como Letras com 16 (22,22\%); Pedagogia 10 
(13,89\%); Química 8 (11,11\%); Matemática, Geografia e História com 5 (6,94\%) cada; Ciências Biológicas com 3 (4,17\%) e Física, com 2 (2,78\%). Saindo da grande área ensino tiveram: Enfermagem com 3 (4,17\%); Administração, Sistema de Informação e Gestão Desportiva e Lazer com 2 (2,78\%) cada. Cursos diversos de outras áreas, contou-se cada um 1 - Logística, Estatística, Educação Física, Psicologia, Odontologia, Comunicação Social, Processos Gerenciais e Estudos Sociais, totalizando 8 (11,11\%). Com $1(1,39 \%)$ participante que não informou a sua graduação principal. Dados esses dispostos na Tabela 1 .

Tabela 1 - Distribuição absoluta e percentual dos cursos de graduação dos participantes da pesquisa, EaD - UECE, 2018.

\begin{tabular}{lcc}
\hline CURSO DE GRADUAÇÃO & n & \% \\
\hline Grande Área de Ensino & & 22,22 \\
\hline Letras & 16 & 13,89 \\
Pedagogia & 10 & 11,11 \\
Química & 8 & 6,94 \\
Matemática & 5 & 6,94 \\
Geografia & 5 & 6,94 \\
História & 5 & 2,78 \\
Física & 2 & 4,17 \\
Ciências Biológicas & 3 & \\
\hline Outras Áreas & & 4,17 \\
\hline Enfermagem & 3 & 2,78 \\
Administração & 2 & 2,78 \\
Sistema de Informação & 2 & 2,78 \\
Gestão Desportiva e Lazer & 2 & 11,11 \\
Cursos diversos & 8 & 1,39 \\
Não informou & 1 & 100 \\
\hline Total & 72 & \\
\hline
\end{tabular}

Fonte: elaboração dos autores.

Ressalta-se o poder da $\mathrm{EaD}$ como ferramenta de ensino na atualidade, devendo ser usada não somente por professores do ensino fundamental, médio e superior, mas buscada por profissionais de Cursos diversos $(11,11 \%)$ e de Enfermagem $(4,17 \%)$ na presente pesquisa. Os autores Araújo et al. (2013) evidenciaram que tem sido valiosa a contribuição dos programas de pós-graduação para a qualificação de profissionais do campo de ensino, da pesquisa e áreas diversas, formando, assim, um quadro de especialistas cuja atuação competente e dedicada se faz não só no âmbito 
teórico, como também no prático. Com esses dados obtidos no presente estudo, percebese que o mercado de trabalho vem sofrendo alterações decorrentes da globalização, tornando-se cada vez mais instável, sendo os profissionais constantemente desafiados pela competitividade.

Foram interrogados quais os níveis de pós-graduações que os participantes da pesquisa tinham, obtendo-se que 41 (56,94\%) ainda estavam concluindo a especialização em EaD pela UECE, 16 (22,22\%) já haviam concluindo outra (s) especialização (es), 14 (19,44\%) tinham nível de mestrado e apenas 1 (1,39\%) participante informou possuir doutorado. Dados que estão expressos no Gráfico 3.

\section{Gráfico 2 - Distribuição percentual dos participantes quanto a pós-graduação, EaD} - UECE, 2018.

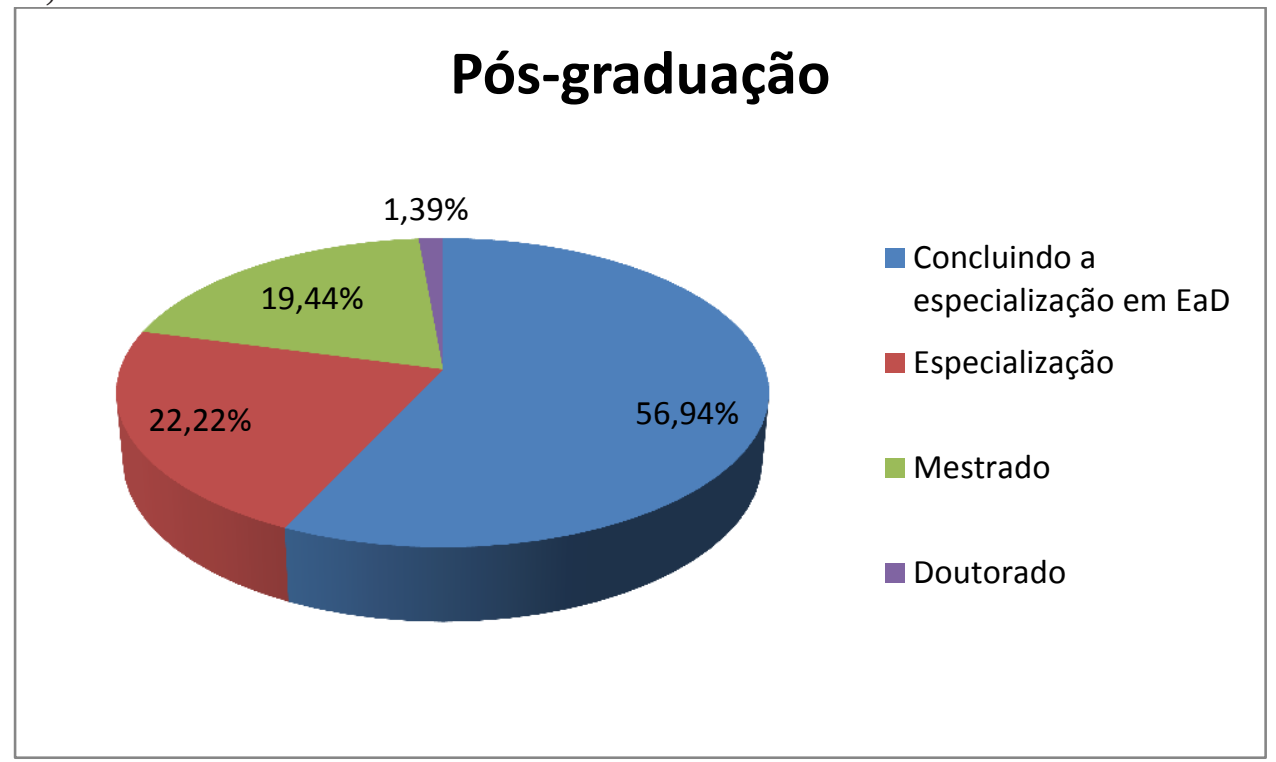

Fonte: elaboração dos autores.

Não se pode deixar de mencionar a penetração da EaD no meio acadêmico, representado nesta pesquisa por participantes que demonstraram seguir também a carreira stricto sensu: Mestrado (19,44\%) e Doutorado (1,39\%). Para se compreender a dimensão dessa questão, recentemente, o Decreto $n^{\circ}$ 9.057, de 2017 desburocratizou o credenciamento e o recredenciamento de Instituição de Ensino Superior (IES) para o uso da EaD em seus cursos de graduação e pós-graduação lato sensu. A oferta da pósgraduação stricto sensu, mestrados e doutorados, ainda é tabu para o Ministério da Educação, via Coordenação de Aperfeiçoamento de Pessoal de Nível Superior 
(CAPES), órgão encarregado de avaliar e supervisionar esse nível de ensino. Contudo, esse decreto já é um avanço extraordinário para a oferta dos cursos de graduação bacharelados, licenciaturas e tecnólogos - e lato sensu, em nível de especialização, na modalidade $\mathrm{EaD}$.

\subsection{Dados dos estilos de aprendizagem}

O algoritmo de pesquisa VARK identificou dentre os 25 possíveis, 11 estilos de aprendizagem nos participantes da pesquisa. $\mathrm{O}$ mais prevalente dos estilos foi o VARK Type One com 33 (45,83\%), seguido pelos V mild e K mild com 8 (11,11\%) cada. Esses e outros dados estão exibidos na Tabela 2.

Tabela 2 - Distribuição absoluta e percentual dos estilos de aprendizagem dos participantes da pesquisa, EaD - UECE, 2018.

\begin{tabular}{lcc}
\hline VARK Standard Algorithm & $\mathrm{n}$ & $\%$ \\
\hline UNIMODAL & 8 & 11,11 \\
V mild & 3 & 4,17 \\
V strong & 4 & 5,56 \\
A mild & 4 & 5,56 \\
A strong & 3 & 4,17 \\
R mild & & 11,11 \\
K mild & 8 & \\
& & \\
POLIMODAL & & 1,39 \\
Bimodal & & 1,39 \\
A mild, R mild (AR) & 1 & 0,0 \\
Trimodal & 1 & $45,83 \%$ \\
Panmodal & 0 & $4,17 \%$ \\
VARK Type One & 33 & $5,56 \%$ \\
VARK Transition & 3 & 100,00 \\
VARK Type Two & 4 & \\
TOTAL & & \\
\hline Fon & & \\
\hline
\end{tabular}


Muito se discute sobre como é que os alunos aprendem, bem como sobre as suas dificuldades de aprendizagem e como essas mesmas dificuldades podem ser colmatadas. É ao pensar em tudo isto que surgem os estilos de aprendizagem e a percepção sobre a existência deles faz com que o professor entenda e possa ajudar os alunos a entenderem melhor e com o menor grau de dificuldade os conteúdos, de acordo com as suas preferências e da melhor forma possível (CUNHA, 2015).

A prevalência do estilo de aprendizagem VARK Type One sobre os demais estilos, demonstra o perfil dos participantes da presente pesquisa, os quais mais olham para as informações que devem ser apreendidas ou transmitidas e escolhe o modo que acreditam ser o melhor para aquela situação. Nesse estilo de aprendizagem o indivíduo se adapta a necessidade, logo, ele é flexível em sua preferência. Ao contrário do estilo VARK Type Two, que foi encontrado em 5,56\% dos participantes, em que o indivíduo é o que se pode chamar de cuidadoso ou cauteloso, fazendo a combinação de modos para tomar decisões, aprender e apresentar algo para outras pessoas. Esse indivíduo age com reforço, tendo uma visão mais ampla ao agir. Caso não use todos os modos em que acredita, pode não aprender como deveria ou desejaria, tornando-se inseguro. Logo, o aluno/professor VARK Type Two pode ter a fama de lento, que dependendo do ponto de vista de resultado e de tempo, pode ser uma desvantagem ou não. Tanto o estilo VARK Type One como o VARK Type Two são considerados polimodais, tendo ainda o estilo VARK Transition (4,17\%) como meio termo entre esses dois estilos (FLEMING; MILLS, 1992; FLEMING, 1995; FLEMING; BAUME, 2005; FLEMING, 2016).

Distanciando-se da presente pesquisa, os estilos de aprendizagem mais prevalentes na pesquisa de Carlos (2017) foram representados pelo código K mild com 13,9\%, seguido de ARK com 12,6\% e VARK Type One com 11,1\%.

As estatísticas VARK não ajudam a decidir, pois é um resultado e não uma causa. Sem usar o algoritmo VARK, os dados brutos de Sousa (2017) revelaram que $21,8 \%$ dos respondentes tendenciaram para Visual, 25,6\% para Aural, 24,0\% para Leitura/Escrita e 28,7\% para Sinestésico. Nessa distribuição, provavelmente, há opções simultâneas entre Visual/Aural, Visual/Sinestésico e outros. Mas salienta-se que somente o algoritmo VARK é que pode identificar os estilos de aprendizagem dos 
indivíduos como se deve. Com isso, denuncia-se que as pesquisas que envolvem a temática do presente estudo são restritas, carecem de validação e apresentam viés.

Houve uma ligeira preferência dos estilos V mild e K mild sobre os demais estilos unimodal identificados na presente pesquisa. $\mathrm{O}$ que pode ser explicado pela necessidade humana de ver na prática e praticar o que foi estudado para melhor assimilarem um assunto. É certo que os vídeos preenchem bem esse requisito. Diante disso, Silva e Oliveira (2010) discorrem que o uso dos recursos midiáticos, em especial o vídeo, possibilita o despertar da criatividade à medida que, estimula a construção de aprendizados múltiplos, em consonância com a exploração da sensibilidade e das emoções dos alunos, além de contextualizar conteúdos variados.

Há de se ressaltar a presença tímida de participantes A mild e A strong, com 5,56\% cada na presente pesquisa. Essas pessoas sentem a necessidade de ouvir e dialogar como estratégias para melhor aprenderem e ensinarem. Considerando a abordagem interacionista de Piaget, Dias e Lima (2010) discorrem que as estruturas cognitivas são ativadas por motivações afetivas, ou seja, o indivíduo assimila os elementos que o afetam. Dessa forma, devido à capacidade de persuasão da linguagem audiovisual como influenciadora de sentido, é importante aproveitá-la no processo educativo.

\subsection{Dados das respostas e questões}

Conforme as questões foram postas no sentido de interpretação e resolução para identificar o estilo de aprendizagem dos participantes da pesquisa, pode-se dizer que houve uma preferência sobre determinadas opções de respostas. Das 16 questões propostas, em sequência aleatória, em 8 os participantes tomavam a posição de professor e 8 de aluno, tendo quatro opções de respostas (V, A, R e K), podendo escolher mais de uma ou nenhuma. Logo, o somatório delas pode ter sido diferente do número dos 72 participantes da pesquisa. Tais dados estão representados pelos Quadros 1 (aluno) e 2 (professor). Para entendê-las faz-se necessário consultar o Anexo 1. (Questionário).

Para a Questão 1, a opção R foi a preferida com 43 (59,7\%), Questão 7 - K com 50 (69,4\%), Questão 9 - K com 38 (52,8\%), Questão 10 - R com 30 (42,3\%), 
Questão 11 - A com 42 (58,3\%), Questão 13 - K com 48 (66,7\%), Questão 14 - R com 32 (44,4\%), Questão 16 - R com 29 (40,3\%).

Quadro 1 - Distribuição das respostas segundo as questões, tomando-se a posição de aluno, EaD - UECE, 2018.

\begin{tabular}{|l|l|l|l|l|l|l|l|l|}
\hline \multirow{2}{*}{ QUESTÕES } & \multicolumn{7}{|c|}{ RESPOSTAS } \\
\cline { 2 - 9 } & $\mathrm{V}$ & & $\mathrm{A}$ & & $\mathrm{R}$ & & $\mathrm{K}$ & \\
\cline { 2 - 10 } & $\mathrm{n}$ & $\%$ & $\mathrm{n}$ & $\%$ & $\mathrm{n}$ & $\%$ & $\mathrm{n}$ & $\%$ \\
\hline Questão 1 & 15 & 20,8 & 25 & 34,7 & 43 & 59,7 & 16 & 22,2 \\
\hline Questão 7 & 15 & 20,8 & 25 & 34,7 & 5 & 6,9 & 50 & 69,4 \\
\hline Questão 9 & 15 & 20,8 & 28 & 38,9 & 17 & 23,6 & 38 & 52,8 \\
\hline Questão 10 & 22 & 31,0 & 19 & 26,8 & 30 & 42,3 & 19 & 26,8 \\
\hline Questão 11 & 13 & 18,1 & 42 & 58,3 & 5 & 6,9 & 31 & 43,1 \\
\hline Questão 13 & 13 & 18,1 & 17 & 23,6 & 15 & 20,8 & 48 & 66,7 \\
\hline Questão 14 & 20 & 27,8 & 22 & 30,6 & 32 & 44,4 & 16 & 22,2 \\
\hline Questão 16 & 24 & 33,3 & 20 & 27,8 & 29 & 40,3 & 19 & 26,4 \\
\hline
\end{tabular}

Fonte: elaboração dos autores.

Para a Questão 2, a opção A foi a preferida com 36 (50,0\%), Questão 3 - R com 38 (52,8\%), Questão 4 - K com 28 (38,9\%), Questão 5 K com 35 (50,0\%), Questão 6 - R com 41 (57,7\%) Questão 8 - R com 40 (55,6\%), Questão 12 - V com 37 (52,1\%), Questão 15 - A com 45 (62,5\%).

Quadro 2 - Distribuição das respostas segundo as questões, tomando-se a posição de professor, EaD - UECE, 2018.

\begin{tabular}{|l|l|l|l|l|l|l|l|l|}
\hline \multirow{2}{*}{ QUESTÕES } & \multicolumn{7}{|c|}{ RESPOSTAS } \\
\cline { 2 - 10 } & $\mathrm{V}$ & & $\mathrm{A}$ & & $\mathrm{R}$ & & $\mathrm{K}$ & \\
\cline { 2 - 10 } & $\mathrm{n}$ & $\%$ & $\mathrm{n}$ & $\%$ & $\mathrm{n}$ & $\%$ & $\mathrm{n}$ & $\%$ \\
\hline Questão 2 & 18 & 25,0 & 36 & 50,0 & 16 & 22,2 & 21 & 29,2 \\
\hline Questão 3 & 9 & 12,5 & 28 & 38,9 & 38 & 52,8 & 20 & 27,8 \\
\hline Questão 4 & 27 & 37,5 & 20 & 27,8 & 6 & 8,3 & 28 & 38,9 \\
\hline Questão 5 & 13 & 18,6 & 24 & 34,3 & 15 & 21,4 & 35 & 50,0 \\
\hline Questão 6 & 9 & 12,7 & 21 & 29,6 & 41 & 57,7 & 18 & 25,4 \\
\hline
\end{tabular}




\begin{tabular}{|l|l|l|l|l|l|l|l|l|}
\hline Questão 8 & 4 & 5,6 & 24 & 33,3 & 40 & 55,6 & 24 & 33,3 \\
\hline Questão 12 & 37 & 52,1 & 10 & 14,1 & 23 & 32,4 & 18 & 25,4 \\
\hline Questão 15 & 18 & 25,0 & 45 & 62,5 & 9 & 12,5 & 10 & 13,9 \\
\hline
\end{tabular}

Fonte: elaboração dos autores.

Para se chegar ao diagnóstico dos estilos de aprendizagem dos 72 participantes da pesquisa, analisou-se pelo algoritmo VARK as alternativas para V, A, $\mathrm{R}$ e K, diante das 16 questões disponibilizadas no questionário instrumento de coleta de dados da pesquisa. Percebeu-se ao longo da aplicação do mesmo, a preferência por determinada resposta para específica questão. Assim foi com a Questão 7 com 69,4\% e a Questão com 13 66,7\%, ambas para a opção que remetia ao estilo K - sinestésico. Observou-se ainda que nas questões em que os participantes tomavam a posição de aluno, somente prevaleceram as opções K ou R. Apesar de ainda prevalecerem as opções R e K, diferentemente, tomando a posição de professor, ocorreu que na Questão 2 e 15, a opção A foi a preferida com 50,0\% e 62,5\%, respectivamente. E ainda, na Questão 12 os participantes demonstraram preferir mais ver - V com 52,1\%. Com isso, salienta-se que foi justamente a compilação da tomada de decisão do participante sobre as diferentes questões, com diferentes situações e diferentes opções, que geraram a conclusão de cada estilo de aprendizagem.

Justifica-se que um leigo, ao observar os dados ainda brutos das respostas dos questionários poderia achar que os prováveis estilos de aprendizagem dos participantes da presente pesquisa seriam em sua maioria os estilos Visual (V) e Sinestésico (K) e variações, o que não ocorreu ao se aplicar a análise pelo algoritmo VARK. Portanto, essa análise é relativa, daí a abertura para os participantes marcarem uma ou mais opções nas questões, ou nenhuma delas.

Devidos às influências das TICs, as pessoas estão cada vez mais buscando todas as estratégias e recursos para ensinarem e aprenderem melhor. Uma prova é o predomínio das opções $\mathrm{R}$ e $\mathrm{K}$ na análise absoluta e a prevalência do estilo de aprendizagem VARK type one na presente pesquisa. Ou seja, os indivíduos gostam de ler e sentem a necessidade de praticar, contudo ainda querem ver e discutir, conforme achem necessário. 


\subsection{Dados da disciplina Teorias da Aprendizagem}

A disciplina Teorias da aprendizagem, como a terceira do curso de especialização referente, foi dividida em 5 unidades: I - A teoria behaviorista da aprendizagem: processos de condicionamento, II - O Humanismo na aprendizagem, III A teoria genética da aprendizagem (Jean Piaget), IV - Abordagem Sócio-histórica de Vygotsky, V - Andragogia: reflexões em torno da aprendizagem de adultos. Para cada uma dessas unidades foi disposta uma apostila e foi proposta também uma atividade que valia uma nota, a qual compunha a média final do pós-graduando. Foi recomendada ao aluno a busca por livros e vídeos para complementar o aprendizado. Dados que estão orgnizados no Quadro 3.

Quadro 3 - Relação do material de estudo e atividades da disciplina teorias da aprendizagem, EaD - UECE, 2018.

\begin{tabular}{|c|c|c|c|}
\hline $\begin{array}{c}\text { DISCIPLINA - } \\
\text { TEORIAS DA } \\
\text { APRENDIZAGEM }\end{array}$ & $\begin{array}{c}\text { MATERIAL } \\
\text { DIDÁTICO } \\
\text { (PDF) }\end{array}$ & ATIVIDADE & RECOMENDAÇÕES \\
\hline $\begin{array}{l}\text { UNIDADE I - A teoria } \\
\text { behaviorista da } \\
\text { aprendizagem } \\
\text { (processos de } \\
\text { condicionamento) }\end{array}$ & 1 apostila & $\begin{array}{l}1 \text { fórum de } \\
\text { discussão }\end{array}$ & $\begin{array}{l}3 \text { livros } \\
5 \text { vídeos }\end{array}$ \\
\hline $\begin{array}{c}\text { UNIDADE II - O } \\
\text { Humanismo na } \\
\text { aprendizagem }\end{array}$ & 1 apostila & 1 Wiki & $\begin{array}{l}3 \text { livros } \\
2 \text { vídeos }\end{array}$ \\
\hline $\begin{array}{l}\text { UNIDADE III - A } \\
\text { teoria genética da } \\
\text { aprendizagem (Jean } \\
\text { Piaget) }\end{array}$ & 1 apostila & $\begin{array}{l}1 \text { produção } \\
\text { textual } \\
\text { individual }\end{array}$ & $\begin{array}{l}11 \text { livros } \\
4 \text { vídeos }\end{array}$ \\
\hline $\begin{array}{c}\text { UNIDADE IV - } \\
\text { Abordagem Sócio- } \\
\text { histórica de Vygotsky }\end{array}$ & 1 apostila & $\begin{array}{l}1 \text { fórum de } \\
\text { discussão }\end{array}$ & $\begin{array}{l}6 \text { livros } \\
2 \text { vídeos }\end{array}$ \\
\hline
\end{tabular}




\begin{tabular}{|c|c|c|c|}
\hline UNIDADE V - & 1 apostila & 1 Levantamento & 3 livros \\
Andragogia: reflexões & & bibliográfico & 2 vídeos \\
em torno da & & \\
aprendizagem de \\
adultos
\end{tabular}

Fonte: elaboração dos autores.

Diante do número de participantes unimodais encontrados na presente pesquisa, indica-se para as IES a disposição de materiais didáticos e atividades que preencham a necessidade desses aprendentes nos cursos de EaD.

Argolo et al. (2009) afirmam que a proposta da teoria humanista está voltada para uma abordagem centrada na pessoa, em que o professor é um facilitador não interferindo diretamente no campo cognitivo e afetivo do aluno que é um agente ativo e tem liberdade para escolher os caminhos que deseja seguir para subsidiar a construção do seu próprio conhecimento.

O que proporciona a aprendizagem não é o uso ou não de novas tecnologias, mas sim o método de ensino e a escolha correta dos materiais adequados para cada situação. O aluno mesmo como aprendiz autônomo deve receber da instituição de ensino $\mathrm{EaD}$ os mais diversos recursos e fontes de conteúdo, sempre bem selecionados e produzidos, além de proporcionar suporte educacional suficiente para sanar possíveis dúvidas (PACHECO; COELHO, 2012).

Realizar esta pesquisa com participantes em sua maioria com graduação na área de educação, a exemplo de Letras com 22,22\% e Pedagogia com 13,89\%, mostra que enquanto professor toma-se uma posição e se aluno toma-se outra diferente, dada as prevalências paras as opções $\mathrm{V}, \mathrm{A}, \mathrm{R}$ ou $\mathrm{K}$ demonstradas.

Não é indicado realizar correlações estatísticas para saber se os estilos de aprendizagem dos indivíduos têm a ver com o êxito em provas e avaliações (FLEMING; MILLS, 1992; FLEMING, 1995; FLEMING; BAUME, 2005; FLEMING, 2016). Neste sentido, optou-se por escolher uma única disciplina, no caso a Teorias da Aprendizagem, aquela que justamente teve o maior índice de recuperação, para saber se o material de estudo e atividades estavam de acordo com os estilos de aprendizagem dos 
alunos da especialização. Logo, para superar as fragilidades do método VARK, optou-se por buscar dados e elementos que complementassem a pesquisa.

Quanto ao material didático analisado ser uma apostila em PDF, de Portable Document Format (Formato Portátil de Documento), observou-se certa coerência com os estilos de aprendizagem dos pós-graduandos, pois estes, sendo em sua maioria de estilo VARK Type One, buscam estratégias de estudo ou ensino conforme a necessidade. Mas é cabível perguntar como abastecer a preferência para os estilos unimodal? Respondendo, as apostilas disponibilizadas dispunham de links que comunicavam o aluno com o mundo chamado internet. Além demais, houve como recomendações a busca por livros como material complementar, e vídeos para serem abertos a partir do AVA do curso. Condições que em parte cumpre os requisitos propostos por Belisário (2006) como navegabilidade, estrutura e discurso, graças à força da internet. No entanto, não se percebeu o critério lúdico diante das apostilas. Logo, os materiais de estudo analisados não estavam de acordo com o grau mais evoluído de tipo de material proposto por Moran (2018), pois foram considerados estáticos, não disponibilizando um sistema touchscreen e interativo para ligar a comunicação entre alunos e professores conteudistas ou formadores.

Até aqui, nenhum fato justificou seguramente o alto índice de dificuldade na disciplina Teorias Aprendizagem. Infere-se que as intervenções dos tutores poderiam atingir positiva ou negativamente os alunos, mas isso não foi capaz de ser medido pela presente pesquisa. O grau de dificuldade para os participantes aprender as Teorias da Aprendizagem também não foi mensurado. Mas quando se analisou as atividades propostas na disciplina, as quais valiam notas, observou-se que elas, as atividades, estavam a desejar. É que os alunos também têm o estilo preferido de como querem ser avaliados e o método VARK também serve para explicar essas questões.

Assim, uma provável explicação para o índice de recuperação na referida disciplina, talvez esteja na pouca variabilidade dos estilos das avaliações, que no caso foram 2 fóruns de discussão, 1 atividade Wiki, 1 produção de texto individual e 1 levantamento bibliográfico. Tais atividades provavelmente favoreceram mais aqueles indivíduos que têm preferência pela leitura/escrita, estilo de aprendizagem $\mathrm{R}$ e variações, bem como aqueles de estilo polimodal, em especial o VARK Type One, que é o mais adaptável. Para ter comtemplado todos os estilos de aprendizagem dos alunos, 
careceu-se na disciplina de atividades como Podcast, produção de vídeos, debates em aulas presenciais etc. Atividades essas que também cumpririam os requisitos de avaliação e aprendizagem daqueles indivíduos unimodais (V mild - 11,11\%, V strong 4,17\%, A mild - 5,56\%, A Strong - 5,56\%, K mild - 11,1) e bimodal: A mild, R mild (AR) - 1,39\% e A strong, $\mathrm{K}$ mild (AK) - 1,39\%. Daí as avaliações teriam um peso distribuído de forma justa entre os variados estilos de aprendizagem dos pósgraduandos.

O professor-tutor coloca-se como um mediador no processo de ensino aprendizagem, devendo propor a realização de atividades e apoiar sua resolução e não apenas mostrar a resposta correta, incentivando a pesquisa ou oferecendo outras fontes de informação; entendendo o assunto ensinado e a organização do conteúdo; guiando, orientando e apoiando (PIMENTEL, 2006).

Vale destacar a presença possivelmente de alunos vicários nos fóruns, que devido suas características podem não ter ficado em evidência na atividade a receber uma nota. Segundo Mattar (2009, p. 117) "a interação vicária é uma interação silenciosa em que o aluno observa as discussões e os debates, sem deles participar ativamente", ou seja, esses alunos recebem as mensagens sem contribuir/posicionar-se, em nenhum momento sobre a discussão.

Na elaboração das apostilas, Florindo, Batista e Azevedo (2015), evitou-se a simples repetição do que é apresentado em livros, buscando criar um material cuja linguagem fosse facilmente compreendida pelos alunos. Através da organização e planejamento das unidades de aprendizagem/módulo é possível distribuir tarefas como a elaboração do texto, de um vídeo, entre outros materiais de cada unidade, nos quais os assuntos serão tratados de modo articulado (ZANETTI, 2005).

Apesar de toda essa argumentação, os cursos em EaD têm como princípio a Andragogia, em que o indivíduo é autônomo, tendo certa decisão do que aprender. Logo, os materiais de estudo são importantes para direcionar o aluno para aprender, mas não podem ser a única fonte estudada. É preciso buscar outras fontes, sendo a mais recomendada a internet.

$\mathrm{Na}$ internet é possível contar com as Wikis para construções de textos colaborativos, blogs para publicações, acervo multimídia (Youtube) com material de apoio e microblogs (Twitter), que pode ser usado para discussões. Essas ferramentas 
podem ser exploradas pelo professor-tutor no processo de aprendizagem virtual (SOUSA, 2015).

Sobretudo, ainda justifica o grau de dificuldade para entender conteúdos demasiadamente filosóficos como aqueles que envolvem as Teorias da Aprendizagem. Dificuldade essa que pode ter ajudado os pós-graduandos não terem tido tanto êxito nas atividades da disciplina Teorias da Aprendizagem do curso em discussão já referido.

Entende-se que as pessoas não mudam suas preferências de aprendizado facilmente, sendo necessárias grandes influências para mudar certos comportamentos, como a pressão para acompanhar o ritmo de um local de trabalho, o que geraria sucesso. Por outro lado, o modelo VARK não diz nada sobre motivação para aprender. Se um aluno tem uma preferência por aprender usando texto em um modo de leitura não significa que ele terá sucesso em uma avaliação de sucesso acadêmico que usa texto (FLEMING; MILLS, 1992; FLEMING, 1995; FLEMING; BAUME, 2005; FLEMING, 2016).

Ao longo desta pesquisa viu-se a grande escassez de trabalhos científicos com metodologia semelhante (público EaD e método VARK) para compor esta discussão. Por outro lado, faz-se necessária a realização de estudos longitudinais para acompanhar as facilidades ou dificuldades de as pessoas se adaptarem às novas formas de aprendizado e ensino impostos pela sociedade.

É preciso ter uma noção dos estilos de aprendizagem dos prováveis alunos de um curso $\mathrm{EaD}$, para que os instrutores de designers e professores conteudistas produzam materiais didáticos compatíveis com os estilos dos alunos. Isso também é válido para a elaboração das atividades e avaliações. Além de toda a relevância da reflexão produzida, a importância da presente pesquisa residiu na identificação dos prováveis estilos de aprendizagem de futuros alunos de uma especialização como a que a UECE ofertou.

\section{CONSIDERAÇÕES FINAIS}

O perfil dos pós-graduandos que participaram da pesquisa foi sexo feminino, educadores e cursando a primeira pós-graduação. É a força da EaD, que 
através da internet transpõe barreiras, atinge todos indistintamente, ocasionando o acesso ao conhecimento, a qualificação e as oportunidades.

O estilo de aprendizagem predominante na pesquisa foi o VARK Type One, seguido por V mild e K mild. Salienta-se a previsibilidade de uma maior facilidade de lidar com os indivíduos do primeiro tipo, dadas a adaptação e a flexibilidade diante das TICs. E ainda a necessidade que as pessoas têm na atualidade de ver as coisas, tocar e praticar, como integrantes do incio, meio e final do processo de ensino-aprendizagem do qual fazem parte.

O material de estudo parecereu está de acordo parcialmente com os estilos de aprendizagem dos participantes da pesquisa, possibilitando o aluno exercer a andragogia. Sendo essencial a construção da interatividade nos materiais educacionais, e o que os mesmos sejam planejados pelas teorias de aprendizagem e pelos estilos de aprendizagem dos receptores e emissores do processo ensino-aprendizagem.

As atividades propostas como avaliação na disciplina Teorias da aprendizagem estavam mais ligadas à leitura/escritura, havendo a necessidade do uso de atividades contendo recursos audiovisuais para abranger todos os estilos. Isso é um conselho aos professores que não variam as suas formas de avaliar o conhecimento do aluno, o que leva a penalizar aquele que não se encaixa num único perfil de teste.

Perante os resultados obtidos com o estudo dos materiais e atividades, depreende-se que se faz necessário o professor readaptar suas formas preferidas de ensinar e diversificá-las, dados os diferentes estilos de aprendizagens dos alunos, bem como é essencial que os alunos adaptem suas estratégias de estudo alinhadas com suas preferências.

Em tempos de internet o conhecimento é de fácil acesso, e todos, professores e alunos, precisam atualizar-se perante as ferramentas e recursos disponíveis. Contudo, corroborando com parte dos resultados deste estudo, valoriza-se a importância da leitura e escrita, como alicerce básico de qualquer formação educacional.

Este trabalho deixa como legado uma substancial avaliação do curso de especialização em educação à distância: fundamentos e ferramentas, passo para o planejamento e implentação de cursos por vir pela UECE. 


\section{REFERÊNCIAS}

ALMEIDA, M. E. B. Educação à distância na Internet: abordagens e contribuições dos ambientes digitais de aprendizagem. Educação e Pesquisa, São Paulo, v. 29, n. 2, p. 327-340, jul./dez. 2003.

ALVES, L. Educação a distância: conceitos e história no Brasil e no mundo. Revista Brasileira de Aprendizagem Aberta e a Distância, v. 10. p. 83-92. 2011.

AMARAL, F. V. Avaliação: estilos de aprendizagem. Disponível em: http://fernandavbr.wixsite.com/eportfolio-ead/avaliacao Acesso em: 07 out. 2017.

AMARAL, S. F.; BARROS, D. M. V. Estilos de aprendizagem no contexto educativo de uso das tecnologias digitais interativas. In: SIMPÓSIO INTERNACIONAL SOBRE NOVAS COMPETÊNCIAS EM TECNOLOGIAS DIGITAIS INTERATIVAS NA EDUCAÇÃO, 1, 2007, São José dos Campos. Anais eletrônicos. São José dos Campos: [s.n.], 2007. Disponível em:

http://lantec.fae.unicamp.br/lantec/pt/tvdi_portugues/daniela.pdf Acesso em: 05 mai. 2018.

ARAÚJO, M. D. C. et al. Pós-graduação: sua importância para o profissional de Secretariado Executivo. Revista do Secretariado Executivo, Passo Fundo, p. 136-149, n. 9, 2013. Disponível em: seer.upf.br/index.php/ser/article/download/4039/2597. Acesso em: 21 set. 2018.

ASSIS, E.; CRUZ, V. Material didático em EAD: a importância da cooperação e colaboração na construção do conhecimento. Linhas Críticas, Brasília, v. 13, n. 24, out. 2011. Disponível em:

http://seer.bce.unb.br/index.php/linhascriticas/article/view/5349/4457. Acesso em: 15 nov. 2018.

AZEVEDO, A. B. Como a interação entre as pessoas envolvidas na EaD (aluno, professor tutor, professor temático, monitor e outros) pode tornar a aprendizagem mais atraente e significativa? In: CONGRESSO INTERNACIONAL ABED DE EDUCAÇÃO A DISTÂNCIA, 16., 2010, Fortaleza. [S.1.]. . Anais... [S.1.:s.n.], 2010.

BARDIN, L. Análise de conteúdo. São Paulo: Edições 70, 2011.

BELISÁRIO, A. O material didático na educação a distância e a constituição de propostas interativas. In: SILVA, Marco (org). Educação online. 2. ed. São Paulo: Loyola, 2006, p. 137-148.

BOKUMS, R. M.; MAIA, J. F. Relação das Tarefas Pedagógicas Interativas com os Traços de Personalidade dos Professores Atuantes na Educação a Distância. Revista científica em educação a distância, v. 6, n. 2, 2016. 
BRASIL. Constituição (1988). Constituição da República Federativa do Brasil: promulgada em 5 de outubro de 1988. Organização do texto de Juarez de Oliveira. 4. ed. São Paulo: Saraiva, 1990. 168 p. (Série Legislação Brasileira).

Ministério da Educação. O Decreto n ${ }^{\circ} 9.057$ de 25 de maio de 2017. Diário oficial [da] República Federativa do Brasil, Brasília, DF, 26 maio 2017, Seção 1, p. 3.

CARLOS, M. X. Compreendendo alunos brasileiros de graduação em odontologia, via inventário Vark: um estudo transversal. 2017. 86f. Dissertação (Mestrado em Clínicas Odontológicas Integradas) - Faculdade São Leopoldo Mandic, Campinas-SP, 2017.

CASARIN, H. C. S.; CASARIN, S. S. Pesquisa científica: da teoria à prática. Curitiba: Intersaberes, 2012.

CUNHA, A. R. F. Relatório final de prática de ensino supervisionada. 2015. 186 f. Dissertação (Mestrado em Ensino do 1..$^{\circ}$ e 2. ${ }^{\circ}$ Ciclos do Ensino Básico) - Instituto Politécnico de Viana de Castelo, Viana do Castelo, Portugal, 2015.

DIAS, R. S.; LIMA, J. R. Os múltiplos recursos tecnológicos no processo educativo do ensino da geografia. In: COLÓQUIO INTERNACIONAL "EDUCAÇÃO E CONTEMPORÂNEIDADE", 4., . 2010, Laranjeiras-SE. Anais eletrônicos.

Laranjeiras-SE: [s.n.], 2010. Disponível em: http://www.educonufs.com.br/IVcoloquio/. Acesso em: 22 set. 2018.

EFFTING, M. A. O. Material didático impresso em EaD: ferramenta que se estabelece. In: COLOQUIO INTERNACIONAL SOBRE GESTIÓN UNIVERSITARIA EM AMÉRICA DEL SUR, 10., . 2010. Buenos Ares. Anais... Buenos Ares. 2010. p. 1-12.

FLEMING, N. D.; MILLS, C. Not another inventory, rather a catalyst for reflection. To Improve the Academy. Acad Res Fac Instructional Organ Dev., v. 11, p. 137 -49. 1992.

I'm different, not dumb. Modes of presentation (VARK) in the tertiary classroom. In: ZELMER, A. Research and development in higher education, proceedings of the 1995 Annual Conference of the Higher Education and Research Development Society of Australasia. [S.1.]: HERDSA, v. 118, p.308-13. 1995.

.; BAUME, D. Learning Styles Again: VARKing up the right tree! Issue 7.4. Educ Develop., v. 7, p.4-7. 2005.

The 2009 VARK scoring trial. Christchurch: VARK learn limited;

2016. Disponível em: http://vark-learn.com/wpcontent/uploads/2014/08/scoring-trial. Acesso em: 23 ago. 2018. 
FLORINDO, V. A.; BATISTA, S. C. F.; AZEVEDO, C. L. V. R. Elaboração de materiais didáticos para $\mathrm{EaD}$ : análise de apostilas para um curso de pré-cálculo. In: CONGRESSO INTEGRADO DA TECNOLOGIA DA INFORMAÇÃO, 2., 2015. Rio de Janeiro. Anais. Rio de Janeiro: [s.n.], 2015.

GIL, A. C. Como elaborar projetos de pesquisa. 5. ed. São Paulo: Atlas, 2008.

GOMES, R. A análise de dados em pesquisa qualitativa. In: MINAYO, M. C. S. (org.). Pesquisa social: teoria, método e criatividade. 18 ed. Petrópolis: Vozes, 2001.

KOLB, D. A. Experiential learning: experience as the source of learning and development. New Jersey: Prentice-Hall Inc., 1984.

LEONARDO, E. S. L.; MOTA, J. B.; GOMES, S. G. S. Estilos de aprendizagem e sua influência nos aspectos pedagógicos de cursos a distância. In: CONGRESSO DE EDUCAÇÃO SUPERIOR A DISTÂNCIA, 11., 2014. Florianópolis. Anais... Florianópolis: [s.n.], 2014.

LIZOTE, S. A. et al. Análise dos estilos de aprendizagem dos estudantes de ciências contábeis em relação ao desempenho e avaliação docente. In:CONGRESSO BRASILEIRO DE CONTABILIDADE, 20., 2010. Fortaleza. Anais.... Fortaleza: [s.n.], 2010.

LÜDKE, M.; ANDRÉ, M. A pesquisa em educação: abordagens qualitativas. São Paulo: EPU, 1986.

MACEDO, M. A. L. D. Produção de material didático impresso para EaD: estudo da preferência do alunado da Universidade Estadual de Montes Claros. Revista Multitexto, v. 4, n. 1, 2016.

MAIA, J. E. B.; VIDAL, E. M. Educação a distância na UECE: uma proposta estratégica para o Ceará do futuro. 2013. Disponível em:http://www.uece.br/sate/index.php/downloads/category/20-arqchamadapub?download=180\%3Atexto-apoio-2013. Acesso em: 20 set. 2018.

\section{MIGUEL, N. A. de. M-Learning- Aprendizagem com Mobilidade Aplicada à} Educação em Administração. São Paulo: FGV-EAESP, 2015.

\section{MIRANDA, C. S.; MIRANDA, R. Á. De M.; MARIANO, A. S. Estilos de} Aprendizagem e sua inter-relação com as Técnicas de Ensino: Uma Avaliação com o Modelo Vark no Curso de Ciências Contábeis de uma IES no interior paulista. 2007. Disponível em: http://www.anpcont.com.br/site/materia.php?id=36 Acesso em: 07 out. 2017.

MINAYO, M. C. S. O desafio da pesquisa social. In: . (org.); DESLANDES, Suely F.; GOMES, Romeu. Pesquisa social: teoria, método e criatividade. 28. ed. Petrópolis, RJ: Vozes, 2009, p. 9-29. 
MORAN, J. M. O que é Educação a Distância. Disponível em: http:// www.eca.usp.br/prof/moran/dist.htm. Acesso em: 29 jan. 2018.

PACHECO, L. R. E.; COELHO, C. F. O material didático impresso como facilitador na educação a distância. In: SIMPÓSIO INTERNACIONAL DE EDUCAÇÃO À DISTÂNCIA, 2., 2012. São Carlos. Anais... São Carlos: [s.n.], 2012. p.1-7.

PAIXÃO, G. C. Interação e perfil de atuação discente em fóruns de discussão no ensino superior a distância: uma prática pedagógica articulada à luz da teoria humanista de Carl Rogers. Revista Científica de Educação a Distância, v. 8, n. 13, jan. 2016.

PARENTE, F. de A. C.; PINTO, G. A. de T., CAMELO, Z. M. C. Teorias da aprendizagem. Fortaleza: UAB/UECE, 2014. 119p.

PIMENTEL, N. M. Educação à distância. Florianópolis: SEAD/UFSC, 2006.

QUINTANA, A. C.; QUINTANA, C. G. A execução das tarefas virtuais no contexto da educação a distância: um estudo em um curso de graduação em administração. Revista GUAL, Florianópolis, v. 5, n. 2, p. 277-297, ago. 2012.

SANTIAGO, M. A.; PIMENTEL, M. R. A mulher na educação brasileira: do direito prescrito ao conquistado. In: CONGRESSO NACIONAL DE EDUCAÇÃO, 2., 2014, Campina Grande-PB. Anais eletrônicos. Campina Grande-PB: [s.n.], 2014 Disponível em: http://www.editorarealize.com.br/revistas/conedu/anais.php. Acesso em: 21 set. 2018.

SILVA, R. V.; OLIVEIRA, E. M. As possibilidades do uso do vídeo como recurso de aprendizagem em salas de aula do $5^{\circ}$ ano. In: PESQUISA EM EDUCAÇÃO:

DESENVOLVIMENTO, ÉTICA E RESPONSABILIDADE SOCIAL, 5., 2010, Porto Alegre. Anais eletrônicos. Porto Alegre: [s.n.], 2010. Disponível em: www.pucrs.br/ciencias/viali/tic_literatura/artigos/videos/Pereira_Oliveira. Acesso em: 22 set. 2018.

SOUZA, G. M. O. Redes Sociais e usos na EaD. In: NUNES, J. B. C. Souza, G. M. O. (orgs) Tecnologias da informação e aprendizagem. Fortaleza: UAB/UECE, 2015.

\section{ZANETTI, A. Elaboração de materiais didáticos para educação a distância.}

Disponível em: www.pucsp.br/ecurriculum/artigos_v_1_n_dez_2005/vanikenskiartigo.pdf. Acesso em: 24 abr. 2018. 


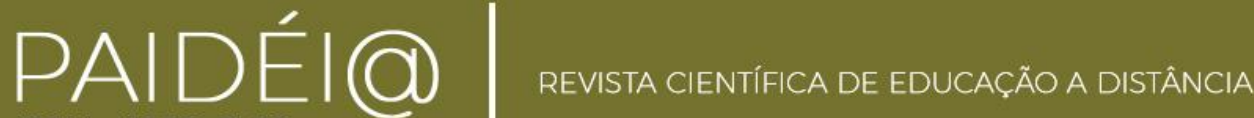

ZELADA, G. O questionário VARK. 2015. Disponível em:

http://www.clevercorp.com.br/blog/2015/01/20/questionario_vark/ Acesso em: 07 out. 2017.

WITKIN, H.A. et al. Field-dependent and field independent cognitive styles and their educational implications. Review of Educational Research, v. 47, p. 1-64, 1977.

\section{Ermano Batista da Costa}

Mestre em Odontologia, Especialista em Educação a Distância pela Universidade

Estadual do Ceará

\section{Halysson Oliveira Dantas}

Doutor em Linguística pela Universidade Federal do Ceará e Professor da

Unifanor/Wyden, Fortaleza, Ceará, Brasil

\section{Tainá Macedo do Val}

Mestre em Ciências da Saúde, Pesquisadora pelo Diretório CNPq/Universidade

Estadual do Ceará - Redes de atenção na perspectiva da saúde coletiva e enfermagem.

Artigo recebido em 03/04/2019

Aceito para publicação em 29/07/2019

\section{Para citar este trabalho:}

COSTA, Ermano Batista da; DANTAS, Halysson Oliveira Dantas; VAL, Tainá Macedo do. ANÁLISE DOS ESTILOS DE APRENDIZAGEM DE PÓS-GRADUANDOS EM EDUCAÇÃO À DISTÂNCIA. Revista Paidéi@. Unimes Virtual. Volume 11 Número 20 - JULHO - 2019 - Disponível em:

http://periodicos.unimesvirtual.com.br/index.php/paideia/index 


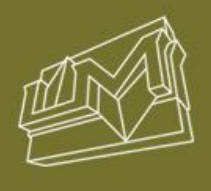

